\title{
Investigation on stick phenomena in metal-on-metal hip joints after resting periods
}

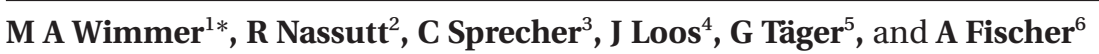

${ }^{1}$ Department of Orthopedic Surgery, Rush University Medical Center, Chicago, Illinois, USA

${ }^{2}$ Biomechanics Section, Hamburg University of Technology, Hamburg, Germany

${ }^{3}$ AO-Research Institute, Davos, Switzerland

${ }^{4}$ Dutch Polymer Institute, Technical University of Eindhoven, Eindhoven, The Netherlands

${ }^{5}$ University of Duisburg-Essen, Medical Center, Department of Trauma Surgery, Essen, Germany

${ }^{6}$ University of Duisburg-Essen, Materials Science and Engineering II, Duisburg, Germany

The manuscript was received on 24 October 2005 and was accepted after revision for publication on 8 November 2005.

DOI: 10.1243/09544119JEIM117

\begin{abstract}
Insufficient understanding of tribological behaviour in total joint arthroplasty is considered as one of the reasons for prosthesis failure. Contrary to the continuous motion input profiles of hip simulators, human locomotion contains motion interruptions. These occurring resting periods can cause stick phenomena in metal-on-metal hip joints. The aim of the present study was to investigate the tribological sensitivity of all-metal bearings to motion interruptions on in vitro test specimens and retrieved implants. Friction and wear with and without resting periods were quantified. Unlike the metal-on-polyethylene joints, the static friction of metal-on-metal joints increased up to $\mu_{\mathrm{s}}=0.3$ with rest, while wear appeared to be unaffected. This effect is caused by the interlocking of firmly adhered carbon layers, which were generated from the protein-containing lubricant through tribochemical reactions. Since more than 80 per cent of the retrieved implants exhibited macroscopically visible carbon layers, the increase in friction presumably also occurs under physiological conditions, which is then transferred to the bone-implant interface. These recurrent tangential stress peaks should be considered for the design features of the cup-bone interface, in particular when larger-sized implant heads are used.
\end{abstract}

Keywords: hip, arthroplasty, friction, wear, metal-on-metal hip joints

\section{INTRODUCTION}

Considerable effort has been directed towards the reduction of artificial joint wear since it has been realized that particulate-induced osteolysis is at the forefront of various total hip failure scenarios. Highly cross-linked ultra-high molecular weight polyethylene, novel types of ceramic bearings, and improved, more precise metal-on-metal (MOM) bearings are just a few examples of biomaterials that have been studied in this context. Because of improved wear properties, these new materials allow a change to increased femoral head sizes in total hip arthroplasty.

*Corresponding author: Section of Tribology, Department of Orthopedic Surgery, Rush University Medical Center, 1653 West Congress Parkway, Chicago, Illinois, 60612, USA. e-mail: markus_a_wimmer@rush.edu
The larger size of the ball-and-socket joint increases the range of motion and reduces the risk of dislocation [1]. Hence, these technological advancements have renewed interest in MOM hip resurfacing in recent years [2]. Here, head diameters of $50 \mathrm{~mm}$ and more are common, which is a considerable increase compared with the conventional $28-32 \mathrm{~mm}$ ball sizes that have been used for many years.

The disadvantage with all these recent technological developments is the lack of long-term track record. Despite known low wear rates, the longevity and long-term effects of the tribosystem are unknown. While there are limited clinical data on hip resurfacing, clinical experience with MOM joints is readily available. High- and low-carbon cobaltchromium-molybdenum (Co-Cr-Mo) alloys have been in use since the 1960s and show good wear resistance $[\mathbf{3}-\mathbf{5}]$. Although the systemic effects of the 
generated wear debris are still under debate [6], the wear particles have a relatively mild influence on the surrounding periprosthetic tissue [7]. Hip simulator studies indicated one-third of the frictional torque for state-of-the-art MOM bearings compared with metal-on-polyethylene (MOP) bearings [8] and head sizes above $36 \mathrm{~mm}$ demonstrated evidence of full fluid-film formation in hip simulator studies [9]. In contrast with simulators, however, human locomotion is non-continuous containing motion inter-

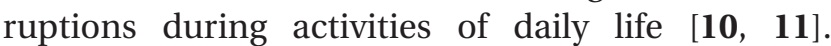
Recently, it has been shown that resting phases can cause stick phenomena in MOM bearings [11] with possible effects on wear and loosening.

In friction tests, 'stiction' of MOM hip replacements after motion interruption was observed previously in McKee-Farrar prostheses and had been attributed to squeezing of the lubricant out of the joint space [12]. This explanation, however, does not withstand recent findings from Nassutt et al. [11], where MOM bearings were considerably more sensitive to motion interruption (with an increase in friction of up to 260 per cent) than any other material combination tested. It was suggested, therefore, that carbide-carbide interaction might be responsible for the frictional rise with possible impacts on wear. If the interlocking of carbides is the relevant mechanism, stick phenomena should vanish after wearingin of the bearing. Wang et al. [13] documented with reference to hip simulator specimens that carbides no longer protruded from the surface after being in use.

The present paper will show that tribochemical reactions are the key to understanding stick phenomena in MOM bearings. It is hypothesized that commonly reported foreign material deposited on the surfaces will cause stick phenomena after resting periods, thereby increasing frictional torque and wear of MOM hip joints. The particular aim of the study was, firstly, to investigate experimentally the tribological sensitivity of the MOM articulation to motion interruption after running in and, secondly, to identify the interlocking bodies on both test specimens and retrieved implants.

\section{MATERIALS AND METHODS}

\subsection{Simulator tests}

In order to undertake the specified measurement task (friction and wear quantification), a custommade wear simulator was used for the experimental part of this investigation [14]. The so-called 'pin-onball' testing device has two concave testing pins per unit, one on each side, which press equatorially on to a total hip replacement head placed between them (Fig. 1). This set-up generates equatorial friction moments at the prosthesis head, produced by two testing interfaces simultaneously. Additionally, the torque sensor is not loaded by contact force, which

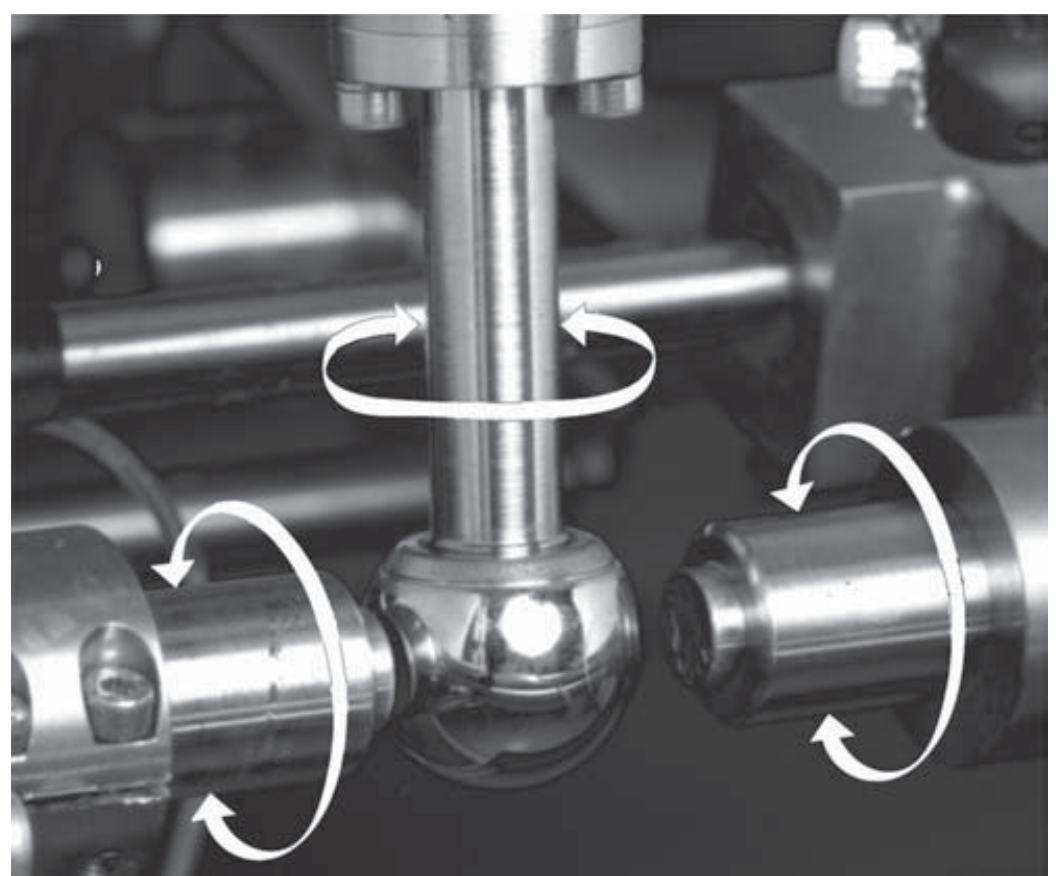

Fig. 1 Pin-on-ball testing unit. The bidirectional motion generates elliptical displacement trajectories on the surfaces 
eliminates cross-talk effects. Therefore, the pin-onball concept allows a precise evaluation of frictional moments at any time. The simulator applies relatively harsh wear conditions; the small pin areas prevent full fluid-film formation, and yet the wear patterns for MOM components are identical with those generated in vivo [15].

A total of $24 \mathrm{Co}-\mathrm{Cr}-\mathrm{Mo}$ pins and $12 \mathrm{Co}-\mathrm{Cr}-\mathrm{Mo}$ balls with a nominal $28 \mathrm{~mm}$ head diameter were put together to form 24 articulations with a radial clearance of $57 \pm 2 \mu \mathrm{m}$. In order to represent the same surface features as the original metal cups, the bearing surfaces of the pins were manufactured in the same fashion as the original cups with an average roughness $R_{\mathrm{a}}=0.077 \pm 0.020 \mu \mathrm{m}$ (measured by laser profilometry). The heads, kindly supplied by Mathys Ltd, Bettlach, Switzerland, were taken from stock and had an average roughness $R_{\mathrm{a}}=0.071 \pm 0.024 \mu \mathrm{m}$. In addition, providing a frictional control group, polyethylene pins were made from GUR 415 and paired with four commercially available $\mathrm{Co}-\mathrm{Cr}$ heads for MOP use (head diameter, $28 \mathrm{~mm}$; clearance, $0.1 \mathrm{~mm})$. The test bodies were placed in a Plexiglas container filled with $120 \mathrm{ml}$ of diluted calf serum. The latter consisted of $80 \mathrm{ml}$ of distilled water containing $9 \mathrm{~g}$ of sodium chloride per litre and $40 \mathrm{ml}$ 'new-born' calf serum, such that the salt (sodium, potassium, and calcium chlorides) and the total protein constituents approximated healthy synovial fluid. Additives included antibiotics to retard bacterial degradation as well as tris-hydroxymethylamine to minimize precipitation of calcium phosphate and to buffer the $\mathrm{pH}$ in the region of 7.6. The lubricating medium was kept at a temperature of $37 \pm 1^{\circ} \mathrm{C}$ and was either cooled or heated.

Two groups were formed of six testing units each for the investigation. In the first group, $2 \times 10^{6}$ cycles were performed continuously. In the second group, the $2 \times 10^{6}$ cycles of pin on hip ball were repeatedly interrupted. Every $30 \mathrm{~s}$ period of oscillation was followed by $15 \mathrm{~s}$ rest. This reflected approximately the average duration as well as the average occurrence of resting periods during routine activity of patients with hip prostheses [11]. In each testing unit, the pins and the hip ball described an oscillating movement of $\pm 30^{\circ}$ at $1 \mathrm{~Hz}$ in a $90^{\circ}$ phase difference, creating elliptical motion trajectories on the contact surfaces [14]. The contact force was set to a constant $750 \mathrm{~N}$ (basic body weight), thus achieving a nominal compression of $6.5 \mathrm{MPa}$. As shown by Clarke et al. [16], such a constant load is reasonable to attempt for hip wear testing.

To determine the wear, $2 \mathrm{ml}$ of serum were extracted at predetermined intervals $\left(50 \times 10^{3}\right.$,
$100 \times 10^{3}, 250 \times 10^{3}, 500 \times 10^{3}, \ldots, 2000 \times 10^{3}$ cycles) and the concentrations of cobalt, chromium, and molybdenum were measured by atomic absorption spectrometry. In order to obtain representative random samples during the test, the serum in the container was thoroughly mixed and homogenized before extracting the sample. Pressurized digestion of metal particles and serum constituents was performed with 1 part serum and 2 parts nitric acid using a microwave. Technical details, the calibration protocol, and the validation of the method using weight loss measurements were reported in [17].

Friction torque measurements were conducted before and after the wear experiments for continuous motion and interrupted motion with different resting periods. The dynamic function coefficient $\mu_{\mathrm{d}}$ and static friction coefficient $\mu_{\mathrm{s}}$ were calculated from the measured torque. All friction torque measurements were performed under uniaxial oscillation of the ball at $1 \mathrm{~Hz}$ and $\pm 20^{\circ}$ angular amplitude. The friction torque was measured for $3 \mathrm{~s}$ during continuous oscillating motion and during motion initiation after predefined periods of rest of $1,5,10,30$, and $60 \mathrm{~s}$ using a torque transducer $(30 \pm 0.025 \mathrm{Nm})$ at $2.5 \mathrm{kHz}$ sampling rate. Six units (three from each group) were investigated. Three test repetitions were stored for each identical pairing under the same pre-defined condition. Similarly, the frictional torque of the MOP pairings was determined.

\subsection{Wear analysis}

After the tribological tests, samples were rinsed in tap water, soaked in acetone, and then ultrasonically cleaned in deionized water. All components were inspected without further preparation using light and scanning electron microscopy. The latter was achieved using an environmental scanning electron microscope XL-30 ESEM FEG (Phillips, Eindhoven, The Netherlands) equipped with an energydispersive X-ray spectrometer for local and area distribution analyses of metallic and non-metallic elements (e.g. carbon and oxygen). Secondary electron (SE) imaging of the sample surfaces was performed using acceleration voltages of 1 or $20 \mathrm{kV}$, whereas backscattered electron (BSE) imaging and qualitative energy-dispersive X-ray analysis were carried out at acceleration voltages of 5 and $20 \mathrm{kV}$. For an acceleration voltage of $1 \mathrm{kV}$, the penetration of the incident electron beam is in the range of a few tens of nanometres for the investigated materials. Thus, in addition to standard high-accelerationvoltage scanning electron microscopy, SE images acquired at $1 \mathrm{kV}$ acceleration voltage show surface 
features in more detail, even at high magnifications. Furthermore, atomic force microscopy (Digital Instruments Dimension 3100, USA) in the tapping mode (non-contact) was employed to analyse the topographical features of the worn surfaces. The macroscopic and microscopic appearances of the worn surfaces were then compared with those of metal-on-metal retrievals.

\subsection{Retrieval analysis}

For the analysis, 55 retrieved metal-on-metal prostheses from 18 male and 29 female patients with a complete medical record and regular follow-ups were obtained from a hospital which had performed 1483 McKee-Farrar total hip replacements between 1970 and 1993 [18]. The implants were manufactured by five different companies and came in three different head sizes: $35 \mathrm{~mm}$ (29 prostheses), $39.5 \mathrm{~mm}$ (7 prostheses), and $41.5 \mathrm{~mm}$ (19 prostheses). All 55 primary operations and revisions were carried out by a single surgeon according to standardized methods [19]. At the time of primary surgery, the patients were on average 61 years old (range, 39-81 years). All of them received the implant because of primary and secondary osteoarthrosis. After a mean in situ time of 11.5 years (range, 1.3-22 years) the hip joint was revised because of aseptic loosening. None of these implants was removed because of excessive wear, i.e. metallosis. Further details of the implants can be obtained from [20].

At the time of removal, the implants were carefully cleaned to remove blood. Caution was taken to avoid touching or damaging the articulating surfaces. All components were then inspected without further preparation by the unaided eye and a magnifying scope (up to $10 \times$ ). In addition to the general characteristics of the wear zone (e.g. location, spread, and appearance etc.), particular interest was paid to the occurrence of non-metallic layers on the articulating surfaces. Three matching cups and heads were prepared for scanning electron microscopy (Hitachi 4100 FESEM, Tokyo, Japan) and viewed in the SE and BSE modes using acceleration voltages from 5 to $20 \mathrm{kV}$. For chemical analyses of the contact surfaces, energy-dispersive X-ray spectroscopy (Oxford ISIS 300, High Wycombe, UK) was employed.

\subsection{Statistics}

Independent-sample and paired-samples $t$ tests have been used to compare friction and wear data between groups and among time intervals within the same group. In addition, to identify significant relationships between variables, linear regression and Spearman correlations (in the case of ordinal data) have been performed. A 0.05 significance level has been used for all tests.

\section{RESULTS}

\subsection{Simulator tests}

At the beginning of the wear test, during oscillating motion, MOP samples showed a lower average dynamic friction coefficient than MOM samples $\left(\mu_{\mathrm{d}}=0.061\right.$ versus $\left.0.098 ; p<0.001\right)$. Maximum friction appeared at the time of motion reversal for both material combinations and was only slightly different from dynamic friction whereby the relative ranking remained unchanged (for MOP, $\mu_{\mathrm{s}}=0.070$ versus MOM, $0.110 ; p<0.001)$. While this static frictional peak increased moderately after resting for up to $10 \mathrm{~s}$ for MOP specimens (Fig. 2), start-up friction of MOM specimens was found to increase significantly with increasing resting duration $(p<0.001)$. It was twice as high after $10 \mathrm{~s}$, and increased by more than 250 per cent after $60 \mathrm{~s}$. Hence, after resting for $60 \mathrm{~s}$, the static friction coefficients were extremely different for MOP and MOM samples $\left(\mu_{\mathrm{s}}=0.096\right.$ versus 0.285 ; $p<0.001$ ). The static friction coefficient was slightly higher for new MOM components than for worn bedded-in components. This difference, however, was not statistically significant for most standstill periods with the exception of $10 \mathrm{~s}$ resting interval $(p<0.05)$.

Metallic wear increased linearly for both the resting and the continuous motion groups with increasing number of cycles (Fig. 3). There was a tendency for a slightly higher wear rate in the resting group (2.32 versus $2.08 \mathrm{~mm}^{3}$ per $10^{6}$ cycles per articulation). However, no significant differences for any measured time interval were found. Regarding the percentile lubricant composition of all units, the ratios of chromium, molybdenum, and cobalt reflected the alloy's composition within \pm 1 wt \%. Note the near constancy of the wear rate over the $2 \times 10^{6}$ cycles (Fig. 3).

\subsection{Macroscopic surface features of experimental and retrieved components}

Macroscopically, by the unaided eye and with the help of a magnifying scope, all experimental MOM specimens (pins and balls) showed distinct layers which were not detected on the MOP samples. The layers generally had a dull appearance and thus were clearly distinguishable from the original metal surfaces. There were similar findings for 46 retrievals, 


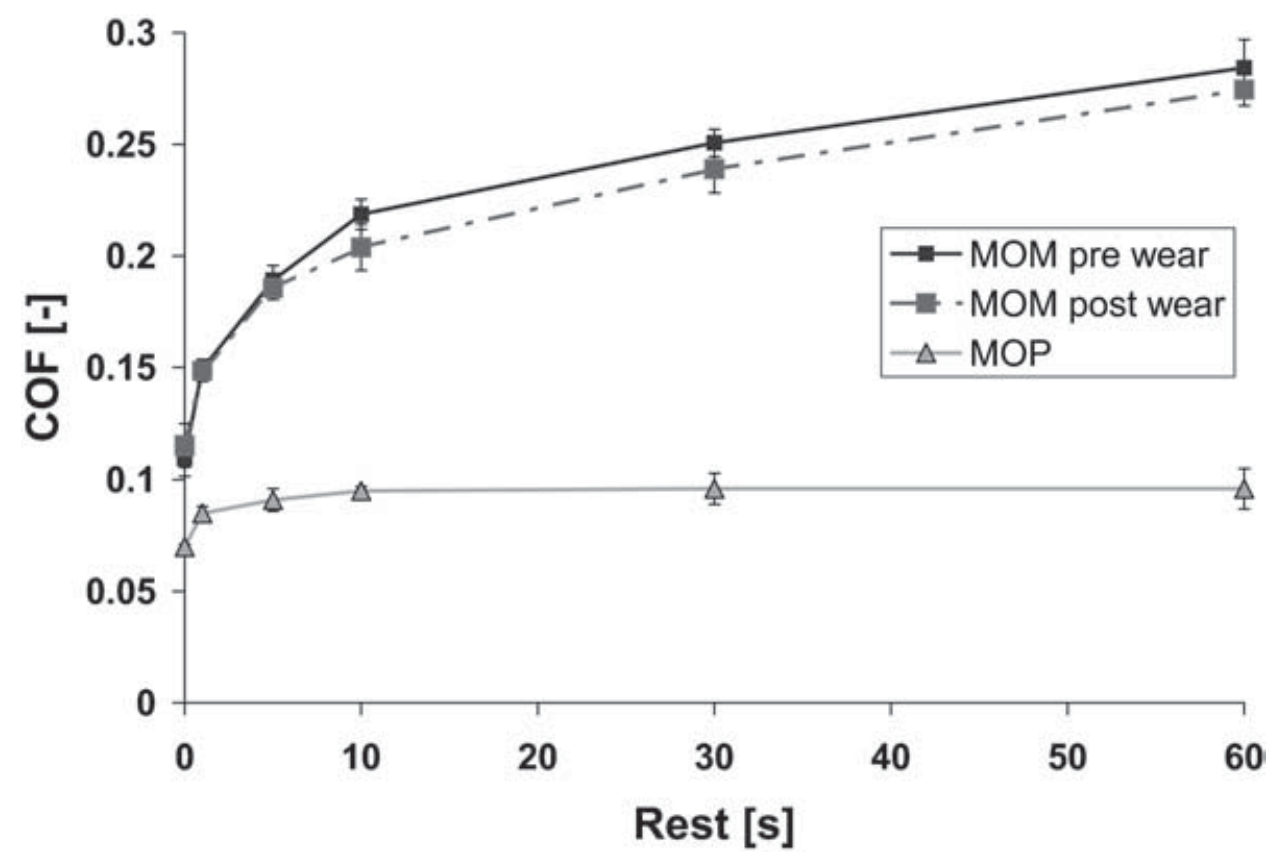

Fig. 2 For all-metal articulations, the static coefficient of friction depends on the resting duration. Start-up friction was twice as high after $10 \mathrm{~s}$ and increased by more than 250 per cent after $60 \mathrm{~s}$ compared with maximum friction during continuous motion. MOP articulations were only a little affected as a result of motion interruption

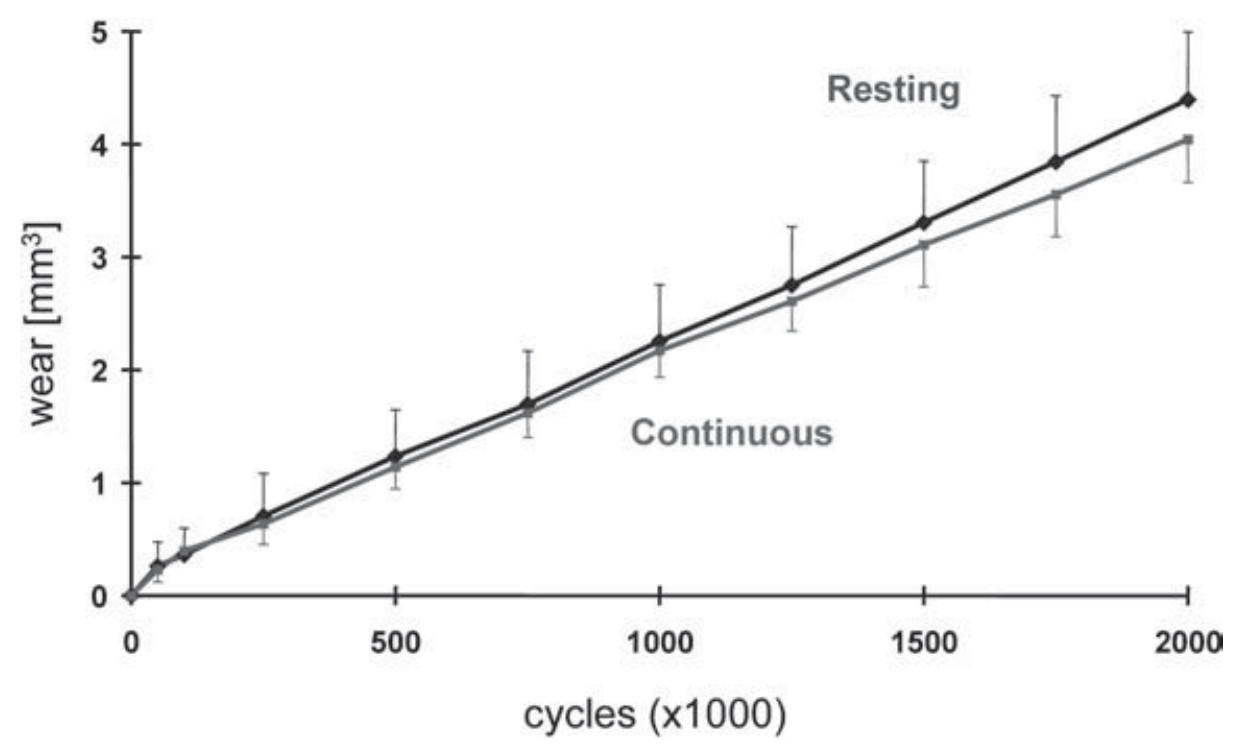

Fig. 3 There was only slightly higher wear for interrupted motion. The difference from continuous motion was not statistically significant

whereby approximately half of the implants displayed these layers on the cup and the head (Table 1). In most cases the layers were found in the polar and/or equatorial regions of head and cup. There was no correlation between time in service (or any other patient-related data) and the occurrence of surface layers. Similarly, neither the head size nor a combinatory model of head size and occurrence of precipitates explained the variance in survivorship.
Furthermore, it was not possible to show a relationship between the occurrence of precipitates and manufacturer (although there were differences ranging from 77 to 90 per cent positive findings), and head size.

\subsection{Microscopic appearance}

The microscopic investigation of the experimental MOM samples revealed that carbides were not pro- 
Table 1 Distribution pattern of macroscopically visible precipitates on retrieved prostheses

\begin{tabular}{llll}
\hline & \multicolumn{3}{c}{ Cup } \\
\cline { 2 - 4 } Head & $\begin{array}{l}\text { Polar } \\
\text { region }\end{array}$ & $\begin{array}{l}\text { Equatorial } \\
\text { region }\end{array}$ & No findings \\
\hline Polar region & 11 & 2 & 1 \\
Equatorial region & 3 & 6 & 2 \\
No findings & 17 & 4 & 9 \\
\hline
\end{tabular}

truding from the articulating surfaces but were mostly below the metal matrix. However, elevated precipitates were present both within and, in larger quantity, at the edges of contact surfaces (Fig. 4). The close-up in Fig. 4 shows that the precipitates adhered rigidly to the surfaces. They consisted mainly of carbon, containing small amounts of sodium, chloride, potassium, calcium, phosphorus, and oxide (Fig. 4). Their shapes varied widely from curved and compact to flat and elongated, with their sizes ranging from a few tens to a few hundred microns in size. Some of them exhibited cracks or were scratched owing to a secondary abrasive event.

Similar findings resulted from examination of retrieved implants. Carbon layers were found not only in the areas with macroscopically dull-looking precipitates but also in the polished contact regions of the implant (Fig.5). As for the experimental samples, the carbon layers were often crossed by abrasive scratches, indicating their involvement in the wear process.

\section{DISCUSSION}

The results of this study have shown that the resting periods had a critical effect on the amount of static friction, but not on the wear of metal-on-metal articulations. Further, it has been demonstrated that the stick phenomenon persists after $2 \times 10^{6}$ cycles of wear. It is therefore suggested that this phenomenon is related to tribochemical reaction products, namely carbon-rich deposits which have been identified on both experimental and retrieved specimens. Since the metal alloy itself contains only small amounts of carbon, these precipitates must be generated by the protein-containing lubricant (i.e. bovine serum or joint fluid).

Foreign layers have been observed in vivo and in vitro by several workers (see, for example, references [20] to [23]) and are usually described as 'calcium phosphate precipitate'. However, these 'deposits'

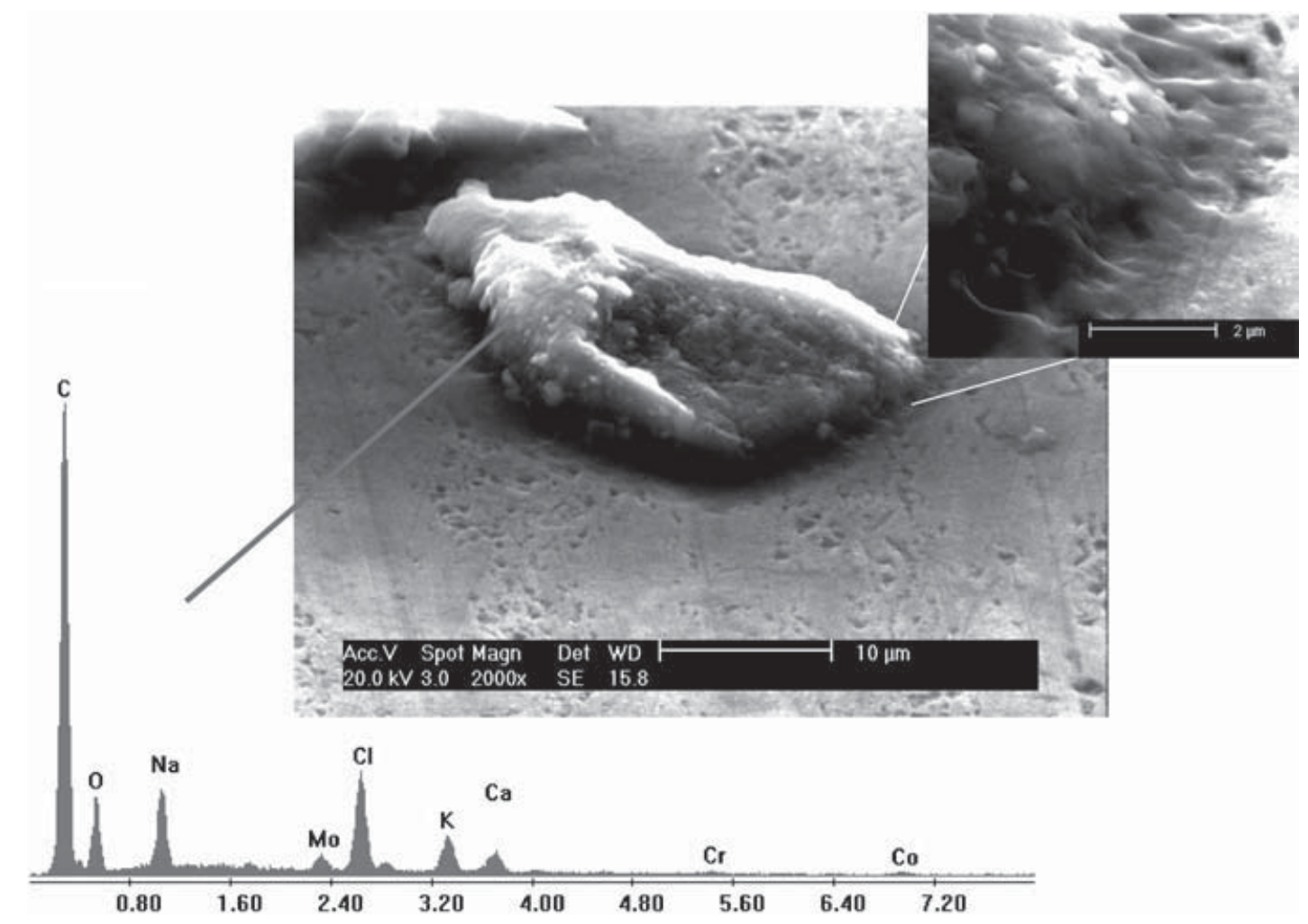

Fig. 4 Microscopic analysis revealed distinct layers which adhered firmly to the metal surfaces (see close-up) (WD, wear depth). They consisted mainly of carbon, containing small amounts of salts from the lubricant 


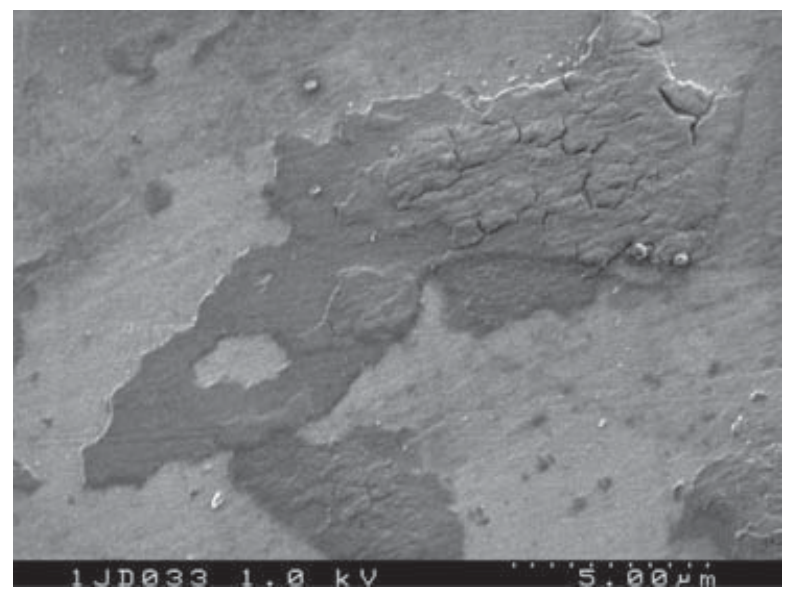

Fig. 5 Similar carbon layers with nearly identical compositions were found on the articulations of retrieved specimens

have generally been regarded as a matter of peripheral importance. Semlitsch et al. [24] were among the first who suspected that tribochemical reactions were behind these observations but the consequences with respect to friction and wear were not further investigated. Tribochemical reactions occur when surfaces in mechanical contact react with the interfacial medium and the environment, resulting in the alternating formation and removal of chemical reaction products at the surfaces. Mechanical and thermal activation of the surfaces due to friction leads to contact spots with an increased chemical reactivity [25]. Those 'hot spots' may experience a temperature increase up to $80^{\circ} \mathrm{C}$ in conventional MOM bearing couples [26]. Although these temperatures last for only a very short time ('flash temperatures'), they are capable of decomposing proteins [15], which then stick rigidly to the surfaces. This change in roughness is likely to increase friction until these layers spall off the surface during motion initiation.

The increase in static friction (or 'stiction') with resting time has been described earlier. Nassutt et al. [11] repeated the static and dynamic friction experiments with tribological pre-conditioning for a variety of joint materials. Already after resting periods of as short as $1 \mathrm{~s}$, Nassutt et al. found significant differences for metal-on-metal couplings and suggested that this stick phenomena may be related to carbidecarbide interaction. Since the 'stiction' effect endures with worn components, the mechanism of the interlocking of carbides seemed implausible. In this study and in the study by Wang et al. [13] it has been shown that carbides are located below the surface after gross wear. Hence, the stick phenomenon may best be explained by interlocking (and spalling off) of decomposed proteins. Because these layers are environmental deposits, there is no associated mass loss of the metal-on-metal joint.

As mentioned above, local surface temperatures of $80{ }^{\circ} \mathrm{C}$ are in effect causing protein deposition [26]. The decomposed proteins will form protein layers, which either adhere firmly to or are incorporated into the tribologically activated metal surfaces. The bonding strength to the substrate (and, thus, the breakaway force) will depend on the resting time given but will not increase beyond 1 min (see Fig. 2). The generation and detachment of precipitates are stochastic processes. Thus, it is possible that accumulated deposits at the edges of contact are disrupted owing to a single movement manoeuvre. The non-discriminated occurrence of precipitates on all investigated head sizes implied that all clinically relevant MOM bearings are involved in this particular process.

Since resting phases up to $30 \mathrm{~s}$ duration in the upright body position represented a main component of the daily activity of total hip arthroplasty patients $[10,11]$, there is clinical relevance behind the findings of this study. Considering metal-onmetal prostheses in patients with $80 \mathrm{~kg}$ body weight, the calculated friction peaks can range from $180 \mathrm{~N}$ up to $600 \mathrm{~N}$ after resting for $30 \mathrm{~s}$ depending on whether motion is started in a single- or two-leg stance*. These recurrent frictional forces generate moments which need to be balanced at the boneimplant fixation. Governed by the implant head diameter, they may be as high as $15 \mathrm{~N} \mathrm{~m}$, assuming a $50 \mathrm{~mm}$ head diameter. In cadaver studies, torque values sufficient to generate instant loosening of the cup, ranged from 6.8 to $46 \mathrm{~N} \mathrm{~m}$ for press-fit cups and up to $170 \mathrm{~N} \mathrm{~m}$ for cemented cups with pegs [28-31]. Although the short friction impulse generated during start-up is probably not adequate to cause instant failure, it may contribute to loosening of cups with bad bone integration.

In conclusion, lubricant deposits formed as a result of tribochemical reactions are likely to produce shear force peaks at the articulation (and thus at the boneimplant fixation) during motion initiation. The generated shear loads are dependent on the head diameter and reasonable precautions with regard to appropriate fixation features of the implants should be taken.

\footnotetext{
*According to Bergmann [27], contact forces between 90 and 300 per cent body weight are generated under conditions of twoleg stance with respect to single-leg stance. Therefore, $F_{\max }=300$ per cent $\times$ body weight $\times 0.25$.
} 


\section{ACKNOWLEDGEMENT}

The authors acknowledge the Robert Mathys Foundation, Bettlach, Switzerland, for support with material and part funding of the study.

\section{REFERENCES}

1 Burroughs, B. R., Hallstrom, B., Golladay, G. J., Hoeffel, D., and Harris, W. H. Range of motion and stability in total hip arthroplasty with 28-, 32-, 38-, and 44-mm femoral head sizes. J. Arthroplasty, 2005, 20 11-19.

2 Schmalzried, T. P. Total resurfacing for osteonecrosis of the hip. Clin. Orthop., 2004, 429, 151-156.

3 Sieber, H. P., Rieker, C. B., and Kottig, P. Analysis of 118 2nd generation metal-on-metal retrieved hip implants. J. Bone Jt Surg., 1999; 81B, 46-50.

4 Anissian, H. L., Stark, A., Gustafson, A., Good, V., and Clarke, I. C. Metal-on-metal bearing in hip prosthesis generates 100 -fold less wear debris than metal-on-polyethylene. Acta. Orthop. Scand., 1999, 70, 578-582.

5 Scholes, S. C., Green, S. M., and Unsworth, A. The wear of metal-on-metal total hip prostheses measured in a hip simulator. Proc. Instn Mech. Engrs, Part H: J. Engineering in Medicine, 2001, 215, 523-530.

6 Urban, R. M., Jacobs, J. J., Tomlinson, M. J., Gavrilovic, J., Black, J., and Peoc'h, M. Dissemination of wear particles to the liver, spleen, and abdominal lymph nodes of patients with hip or knee replacement. J. Bone Jt Surg., 2000, 82A, 457-476.

7 Doorn, P. F., Campbell, P. A., Worrall, J., Benya, P. D., McKellop, H. A., and Amstutz, H. C. Metal wear particle characterization from metal on metal total hip replacements: transmission electron microscopy study of periprosthetic tissues and isolated particles. J. Biomed. Mater. Res., 1998, 42, 103-111.

8 Poggie, R. A., Afflitto, R., and John, K. S. The wear performance of precision Co-Cr-Mo alloy metalon-metal hip bearings. Transactions of the 12th Annual International Symposium for Technology in Arthroplasty, 1999, XI, pp. 1-2 (Rush University Press, Chicago).

9 Smith, S. L., Dowson, D., and Goldsmith, A. A. J. The effect of femoral head diameter upon lubrication and wear of metal-on-metal total hip replacements. Proc. Instn Mech. Engrs, Part H: J. Engineering in Medicine, 2001, 215, 161-170.

10 Morlock, M., Schneider, E., Bluhm, A., Vollmer, M., Bergmann, G., Muller, V., and Honl, M. Duration and frequency of every day activities in total hip patients. J. Biomechanics, 2001, 34, 873-881.

11 Nassutt, R., Wimmer, M. A., Schneider, E., and Morlock, M. M. The influence of resting periods on friction in the artificial hip. Clin. Orthop., 2003, 407, 127-138.

12 Simon, S. R., Paul, I. L., Rose, R. M., and Radin,
E. L. Stiction-friction of total hip prostheses and its relationship to loosening. J. Bone Jt Surg., 1975, 57A, 226-230.

13 Wang, A., Yue, S., Bobyn, J. D., Chan, F. W., and Medley, J. B. Surface characterization of metal-onmetal implants tested in a hip simulator. Wear, 1999, 225-229, 708-715.

14 Wimmer, M. A., Nassutt, R., Lampe, F., Schneider, E., and Morlock, M. M. A new screening method designed for wear analysis of bearing surfaces used in total hip arthroplasty. In Alternative Bearing Surfaces in Total Joint Replacement, ASTM 1346 STP (Eds J. J. Jacobs and T. L. Craig), 1998; pp.30-43 (American Society for Testing and Materials, Philadelphia, Pennsylvania).

15 Wimmer, M. A., Sprecher, C., Hauert, R., Täger, G., and Fischer, A. Tribochemical reaction on metal-onmetal hip joint bearings - a comparison between in-vitro and in-vivo results. Wear, 2003, 255, 1007-1014.

16 Clarke, I. C., Johnson, S., Phipatanakul, W., and Good, V. Effects of hip-loading input on simulated wear of $\mathrm{Al}_{2} \mathrm{O}_{3}$-PTFE materials. Wear, 2001, 250, 159-166.

17 Wimmer, M. A., Artelt, D., Kunze, J., Morlock, M. M., Schneider, E., and Nassutt, R. Friction and wear properties of metal/metal hip joints - application of a novel testing and analysis method. Zeitschr. Matwiss., 2001, 32, 891-896.

18 Täger, K. H. Aspects of loosening in McKee-Farrar endoprostheses. In Technical Principles, Design and Safety of Joint Implants (Eds G. H. Buchhorn and H. G. Willert), 1994 (Hogrefe \& Huber, Bern).

19 Täger, G. Analyse von Metall/Metall-Gleitpaarungen bei Hüftgelenken der ersten Generation im Hinblick auf Grundlagen für eine erneute Anwendung. Thesis, Ludwigs-Maximilians-University, Muich, 1998.

20 Täger, K. H. Untersuchungen an Oberflächen und Neogelenkkapseln getragener McKee-FarrarEndoprothesen. Arch. Orthop. Unfall.-Chir., 1976, 86, 101-113.

21 Plitz, W., Huber, J., and Refior, H. J. Experimentelle Untersuchungen an Metall-Metall-Gleitpaarungen und ihre Wertigkeit hinsichtlich eines zu erwartenden in-vivo-Verhaltens. Orthopäde, 1997, 26, 135-141.

22 Chan, F. W., Bobyn, J. D., Medley, J. B., Krygier, J. J., Yue, S., and Tanzer, M. Engineering issues and wear performance of metal on metal hip implants. Clin. Orthop., 1996, 333, 96-107.

23 McKellop, H., Park, S. H., Chiesa, R., Doorn, P., Lu, B., Normand, P., Grigoris, P., and Amstutz, H. In vivo wear of 3 types of metal-on-metal hip prostheses during 2 decades of use. Clin. Orthop., 1996, 329, Suppl., 128-140.

24 Semlitsch, M., Streicher, R. M., and Weber, $\mathbf{H}$. Verschleißverhalten von Pfannen und Kugeln aus CoCrMo-Gußlegierung bei langzeitig implantierten Ganzmetall Hüftprothesen. Orthopäde, 1989, 18, 377-381. 
25 Bowden, F. P. and Hughes, T. P. Physical properties of surfaces. IV - Polishing, surface flow and the formation of Beilby layer. Proc. R. Soc. A, 1937, 160, $575-587$.

26 Wimmer, M. A., Loos, J., Nassutt, R., Heitkemper, M., and Fischer, A. The acting wear mechanisms on metal-on-metal hip joint bearings - in vitro results. Wear, 2001, 250, 129-139.

27 Bergmann, G., Graichen, F., Rohlmann, A., Verdonschot, N., and van Lenthe, G. H. Frictional heating of total hip implants. Part 1: measurements in patients. J. Biomechanics, 2001, 34, 421-428.

28 Ma, S. M., Kabo, J. M., and Amstutz, H. C. Frictional torque in surface and conventional hip replacement. J. Bone Jt Surg., 1983, 65, 366-370.

30 Lachiewicz, P. F., Suh, P. B., and Gilbert, J. A. In vitro initial fixation of porous-coated acetabular total hip components. A biomechanical comparative study. J. Arthroplasty, 1989, 4, 201-206.

31 Clarke, H. J., Jinnah, R. H., Warden, K. E., Cox, Q. G., and Curtis, M. J. Evaluation of acetabular stability in uncemented prostheses. J. Arthroplasty, 1991, 6, 335-340.

\section{APPENDIX}

\section{Notation}

$\mu_{\mathrm{d}} \quad$ coefficient of dynamic friction

$\mu_{\mathrm{s}} \quad$ coefficient of static friction 